\title{
Combined Treatment of High Hydrostatic Pressure and Cationic Surfactant Washing to Inactivate Listeria monocytogenes on Fresh- Cut Broccoli
}

\author{
Hyuk-Je Woo ${ }^{1}$, Jun-Beom Park ${ }^{1}$, Ji-Hoon Kang ${ }^{1}$, Ho Hyun Chun ${ }^{2}$, and Kyung Bin Song ${ }^{1 *}$ \\ ${ }^{1}$ Department of Food Science and Technology, Chungnam National University, Daejeon 34134, Republic of Korea \\ ${ }^{2}$ Research and Development Division, World Institute of Kimchi, Gwangju 61755, Republic of Korea
}

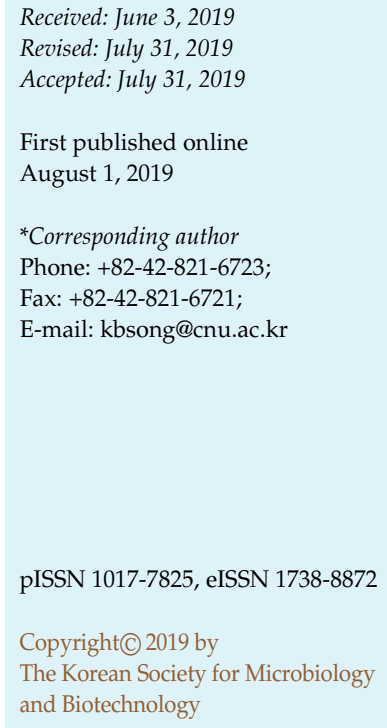

This study was conducted to examine the inactivation effect of the combined treatment of high hydrostatic pressure (HHP; $400 \mathrm{MPa}$ for 1, 3, and $5 \mathrm{~min}$ ) and cationic surfactant washing $(0.05 \%$ benzethonium chloride, BEC) against Listeria monocytogenes inoculated on fresh-cut broccoli (FCB). Washing with BEC at concentrations exceeding $0.05 \%$ resulted in $2.3 \log$ reduction of L. monocytogenes counts on FCB, whereas HHP treatment had approximately 5.55.6 log-reductions regardless of the treatment time. Scanning electron microscopy corroborated microbial enumeration, revealing that the combined treatment was more effective in removing L. monocytogenes from FCB than individual treatment with HHP or BEC. Color and total glucosinolate content were maintained after the combined treatment, although the hardness of the FCB slightly decreased. The results clearly suggest that the combined treatment of HHP and BEC washing has potential value as a new sanitization method to improve the microbial safety of FCB.

Keywords: Cationic surfactant, combined treatment, fresh-cut broccoli, high hydrostatic pressure

\section{Introduction}

The consumption of broccoli has increased gradually due to its having several important nutritional aspects [1]. Particularly, fresh broccoli is beneficial to health because of its high content of phytochemicals [2]. However, the risk of microbial contamination and deterioration in quality of broccoli can occur before and after harvest and with minimal processing [3]. Recently, the United States Food and Drug Administration reported that some of the frozen and fresh-cut broccoli (FCB) products were recalled because of problems related to contamination by Listeria monocytogenes [4]. Therefore, development of a suitable method to ensure the microbiological safety of FCB is needed.

Washing with sanitizers can inactivate foodborne pathogens on fresh-cut produce [5]. In particular, chlorinebased sanitizers, such as $\mathrm{NaOCl}$, have been used in washing fresh-cut produce owing to their efficacy and low cost [6]. Despite several advantages of chlorine-based sanitizers, they are banned in many European countries because they react with organic compounds in water and produce carcinogenic substances, such as trihalomethanes, haloacetic acid, and chloramines [7]. Therefore, many studies have sought to find an alternative $[1,8]$.

Cationic surfactants, such as quaternary ammonium compounds (QACs), have a wide spectrum of inactivation activity against many types of microorganisms. QACs also have various benefits as washing agents, such as lack of color and odor, and their relatively stable to organic compounds $[6,7]$. In spite of the pronounced effectiveness of QACs in the inactivation of pathogenic bacteria, few studies have examined the applicability of QACs as washing agents for fresh-cut produce [8]. It has been reported that benzethonium chloride (BEC), which is a QAC, strongly inactivates various foodborne pathogens, 
particularly the gram-positive bacterium Listeria monocytogenes, on the surface of spinach leaves [8]. Although these results implicated BEC as a potentially valuable sanitizer for fresh produce, the influence of BEC as a wash fluid for broccoli is unknown. In addition, the approach is limited, since washing with $\mathrm{NaOCl}$ or QAC can reduce bacterial viability by 1-2 log colony forming units (CFU)/g only on populations that have contaminated fresh-cut produce [5]. To overcome this limitation, it is necessary to find a suitable combined treatment to enhance the washing effect of sanitizers on the inactivation of foodborne pathogens on fresh-cut produce.

High hydrostatic pressure (HHP) is a non-thermal physical treatment that can replace heat treatment in the food industry. HHP ranging from 400 to $600 \mathrm{MPa}$ can inactivate foodborne pathogens and enzymes without affecting the quality of foods $[9,10]$, and may therefore be a suitable physical treatment to secure the microbial safety of fresh produce [10, 11]. However, the effect of HHP is very dependent on the type of fresh produce, and its effect on broccoli has only been examined in a few studies. Hurdle technology is a disinfection approach that combines chemical/chemical, chemical/physical, or physical/physical treatments to improve the microbial inactivation effect of each single treatment on many types of foods, including fresh-cut produce [12]. The inactivation effects of the combined treatment with several types of chemical or physical treatments on fresh produce have been examined $[1,13,14]$. However, no study has assessed the effect of the combined treatment of HHP and BEC washing on the inactivation of foodborne pathogens contaminating broccoli.

The objective of this study was to examine the inactivation effect of each single or combined treatment with HHP and BEC washing against $L$. monocytogenes inoculated on FCB. Changes in the qualities of FCB including color, browning index, total glucosinolate content, and hardness, were determined after the combined treatment to explore a useful hurdle technology to improve the microbial safety of FCB without affecting the quality.

\section{Materials and Methods}

\section{Bacterial Strain and Inoculum Preparation}

L. monocytogenes (ATCC 15313 and KCTC 13064) cultures were prepared for spot-inoculation onto FCB. Each strain $(0.1 \mathrm{ml})$ was transferred into $25 \mathrm{ml}$ of brain heart infusion broth (Difco Co., USA) and then incubated in a model HB-201MS-2 shaking incubator (Hanbaek Scientific Co., Korea) operating at $150 \mathrm{rpm}$ at $37^{\circ} \mathrm{C}$ for $18 \mathrm{~h}$. The cultures were harvested by centrifugation at $3,000 \times g$ at $4^{\circ} \mathrm{C}$ for $10 \mathrm{~min}$, and the collected bacteria were washed twice using $0.1 \%$ sterilized peptone water (SPW). An L. monocytogenes cocktail inoculum was prepared by combining each bacterial suspension $(10 \mathrm{ml})$ and diluting to produce a suspension with a viable concentration of $7-8 \log \mathrm{CFU} / \mathrm{ml}$.

\section{Sample Preparation}

Broccoli heads (Brassica oleracea var. italica) were purchased from a local mart (Korea) and stored at $4^{\circ} \mathrm{C}$ until used. The samples were cut into square pieces with a uniform size $(3.0 \mathrm{~cm} \times$ $5.0 \mathrm{~cm})$ and weight $(5.0 \pm 0.1 \mathrm{~g})$ using a sterile knife. These FCB samples were placed on an aluminium foil on a clean bench and irradiated with ultraviolet $C$ for $10 \mathrm{~min}$ to reduce naturally existing microorganisms on the surface. The prepared inoculum $(0.4 \mathrm{ml})$ described above was inoculated on the surface of FCB by spotting with a micropipette at 20 to 25 locations. The inoculated samples were placed on the clean bench for $1 \mathrm{~h}$ to allow attachment of the bacteria.

\section{Treatment Conditions}

FCB samples inoculated with L. monocytogenes as just described or not inoculated were vacuum-packed using a vacuum packaging machine for the HHP treatment. The vacuum-packed FCB was placed in a round chamber filled with oil to prevent temperature increase. The chamber was part of the Model R-201 HHP machine (Chemre System, Inc., Korea). The machine used for the experiment was located at the World Institute of Kimchi (Korea). HHP treatment was performed at $400 \mathrm{MPa}$ at $8^{\circ} \mathrm{C}$ for 1,3 , and $5 \mathrm{~min}$.

Inoculated or non-inoculated FCB was washed with $300 \mathrm{ml}$ of prepared washing solutions of distilled water (DW), $\mathrm{NaOCl}$ $(0.02 \%$, Yuhan, Korea), or BEC (Sigma-Aldrich Co., USA) at various concentrations $(0.01,0.03,0.05,0.07$, and $0.1 \%, \mathrm{w} / \mathrm{v})$ in a plastic basket $(15 \mathrm{~cm} \times 19 \mathrm{~cm} \times 6 \mathrm{~cm})$ with mild shaking on a CSKS rotator (Chang-Shin Science, Korea) for $3 \mathrm{~min}$ and dried on a clean bench at $20^{\circ} \mathrm{C}$ for $1 \mathrm{~h}$ to eliminate excess water on the FCB surface. The 3-min washing time for FCB that we used was selected because the allowable washing time of chlorine-based sanitizers is usually less than $5 \mathrm{~min}$ for fresh-cut produce [6]. To determine the optimal concentration of BEC in combination with $\mathrm{HHP}$, the effects of washing with BEC at various concentrations against $L$. monocytogenes on the FCB were compared.

The combined treatment with HHP and $0.05 \%$ BEC washing, which was selected as the optimal concentration based on the experimental results, was sequentially carried out. First, FCB samples were treated with HHP at $400 \mathrm{MPa}$ for 1, 3, and $5 \mathrm{~min}$ and then washed with $0.05 \%$ BEC solution for $3 \mathrm{~min}$. Inoculated and non-inoculated samples were used for the microbial enumeration and quality measurement.

\section{Microbial Analysis}

After the treatments, FCB $(5.0 \pm 0.1 \mathrm{~g})$ samples and SPW $(45 \mathrm{ml})$ were transferred into a sterile stomacher bag and homogenized by a MIX 2 Stomacher (AES Laboratoire, France) for $180 \mathrm{sec}$. One 
milliliter of each homogenized mixture was serially ten-fold diluted with SPW. Diluted samples $(0.1 \mathrm{ml})$ were spread-plated on Oxford medium base (OMB, Difco Co.) and microbial analysis was performed at least five times. All OMB plates were incubated at $37^{\circ} \mathrm{C}$ for $48 \mathrm{~h}$. The microbial count was expressed as log CFU/g and the inactivation effect of the treatment against $L$. monocytogenes on FCB was presented as log-reduction calculated by subtracting the population after each treatment from the initial population of non-treated samples.

\section{Scanning Electron Microscopy (SEM)}

Changes in the population and morphology of L. monocytogenes cells attached on the FCB surface after each single or combined treatment with HHP and BEC washing were observed by SEM using a MERLIN Field Emission-Scanning Electron Microscope (Carl Zeiss, Germany). After the treatments, the FCB surface inoculated with $L$. monocytogenes was sliced with a sterile knife, and the sliced samples were dipped in $0.05 \mathrm{M}$ potassium phosphate buffer ( $\mathrm{pH} 7.2$ ) containing 2.5\% glutaraldehyde for $2 \mathrm{~h}$ to fix the L. monocytogenes on the surface of FCB. After the fixation, the samples were dehydrated successively using ethanol concentrations of $30 \%, 50 \%, 70 \%$, and $100 \%$. The dehydrated samples were dried overnight on a clean bench, fixed with carbon tape, and coated with platinum for $100 \mathrm{sec}$. SEM imaging of the treated and non-treated samples was done at $5 \mathrm{kV}$ and 5,000 $\times$ magnification.

\section{Measurement of Color and Browning Index}

The color changes, especially the Hunter $b$ value that indicates yellowness, in the FCB samples after the treatments were measured with a colorimeter (Minolta, Japan). Changes in browning index of the samples were analyzed as previously described by Kim et al. [15] with minor modifications. Lyophilized FCB powder $(0.1 \mathrm{~g})$ was homogenized with $10 \mathrm{ml}$ of $10 \%$ trichloroacetic acid and the homogenized mixture was reacted at $37^{\circ} \mathrm{C}$ for $2 \mathrm{~h}$. After the reaction, supernatant of the samples was collected by centrifugation at $3,500 \times g, 4^{\circ} \mathrm{C}$ for $10 \mathrm{~min}$. The optical density of each sample was measured at $420 \mathrm{~nm}$ using a model UV-2450 spectrophotometer (Shimadzu, Korea).

\section{Texture Analysis}

The hardness of FCB samples treated with HHP or BEC or with the combination of HHP and BEC washing was determined with a texture analyzer (Stable Micro System Ltd., UK) equipped with a stainless steel cylinder probe. Prepared samples were placed on the stainless holder, and the hardness of the samples was analyzed under the condition of pre- and post-speed $(5 \mathrm{~mm} / \mathrm{s})$ and distance between samples and probe $(5 \mathrm{~mm})$. For the expression of hardness of the samples, the maximum peak recorded during compression test was used.

\section{Total Glucosinolate (GLS) Content}

Total GLS content was measured as described by Mawlong et al.
[16] with some modifications. Briefly, lyophilized sample $(0.1 \mathrm{~g})$ was extracted with $80 \%$ methanol $(1.5 \mathrm{ml})$ in a shaking incubator at $25^{\circ} \mathrm{C}$ for $24 \mathrm{~h}$ and centrifuged at $5,000 \times g$ for $5 \mathrm{~min}$. The supernatant $(0.1 \mathrm{ml})$ was reacted with $0.3 \mathrm{ml}$ of DW and $2 \mathrm{mM}$ sodium tetrachloropalladate $(3 \mathrm{ml})$ for $1 \mathrm{~h}$. The absorbance of the reacted mixture was measured at $425 \mathrm{~nm}$ using a spectrophotometer.

\section{Statistical Analysis}

All experiments were carried out at least five times and the results were expressed as mean \pm standard deviation $(n=5)$. Statistical significance among samples was analyzed using an analysis of variance (ANOVA) and Duncan's multiple range test $(p<0.05)$ with SAS program version 9.4 (SAS Institute Inc., Cary, NC, USA).

\section{Results and Discussion}

\section{Inactivation Effect of BEC Washing}

The effect of washing with different concentrations of BEC on the inactivation of L. monocytogenes on FCB was examined to determine the optimal concentration for the combined treatment with HHP (Fig. 1). Prior to washing, the initial population of $L$. monocytogenes on FCB was $6.79 \log \mathrm{CFU} / \mathrm{g}$. After water washing, the population of L. monocytogenes on FCB slightly decreased to $6.39 \mathrm{log}$ $\mathrm{CFU} / \mathrm{g}$, which was a 0.40 log-reduction (Fig. 1). This result indicated that washing solely with water is not a suitable

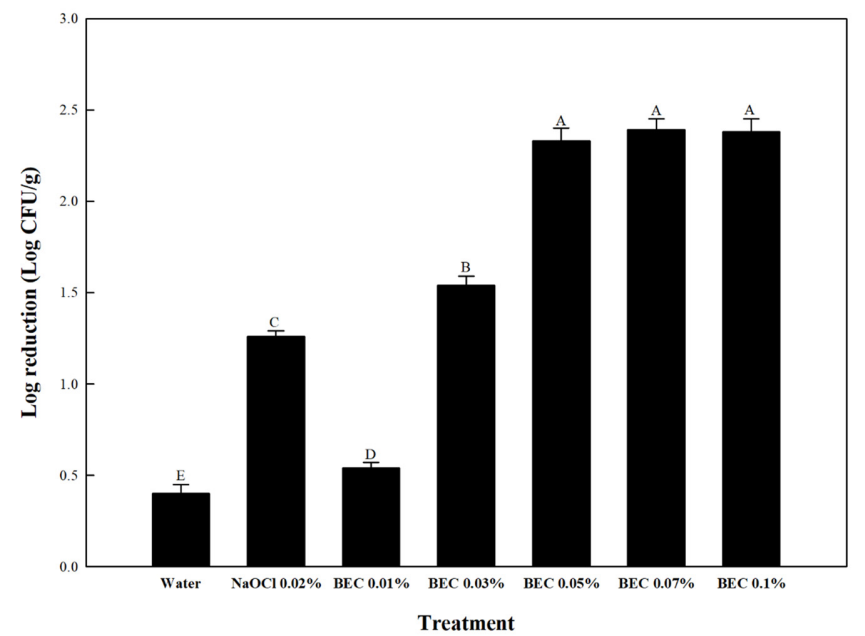

Fig. 1. Log reductions in the population of L. monocytogenes inoculated on fresh-cut broccoli after BEC washing at different concentrations.

Initial population of L. monocytogenes on fresh-cut broccoli was $6.79 \pm$ $0.08 \log \mathrm{CFU} / \mathrm{g}$. BEC: Benzethonium chloride. ${ }^{\mathrm{A}-\mathrm{E}}$ Any means with different letters are significantly different $(p<0.05)$ by Duncan's multiple range test. 
method to remove L. monocytogenes contaminated on FCB. It has also been previously reported that plain water washing without any sanitizer is not sufficient to reduce microorganisms, including pathogens, on the fresh-cut produce surface $[13,17,18]$. Thus, the use of a proper sanitizer for enhancing the inactivation effect of water washing on fresh-cut produce, such as FCB, is needed. In this study, washing with the cationic surfactant BEC as an alternative to the commercial $\mathrm{NaOCl}$ sanitizer to inactivate pathogens on the FCB was evaluated (Fig. 1).

$\mathrm{NaOCl}$ was applied at $0.02 \%$. This concentration is the maximum concentration allowed to contact fresh-cut produce. This treatment was compared to the inactivation effect of BEC on L. monocytogenes attached to FCB. After washing with $0.02 \% \mathrm{NaOCl}$ and $\mathrm{BEC}$ at different concentrations $(0.01 \%, 0.03 \%, 0.05 \%, 0.07 \%$, and $0.1 \%), L$. monocytogenes populations on the FCB decreased by 1.26, $0.54,1.54,2.33,2.39$, and $2.38 \log \mathrm{CFU} / \mathrm{g}$, respectively, compared to non-washed samples (Fig. 1). BEC washing at all concentrations, except $0.01 \%$, produced a significantly $(p<0.05)$ higher inactivation effect than $\mathrm{NaOCl}$ washing. The inactivation mechanism of QACs, including BEC, involves cell membrane damage, perforation, and cell death through electrostatic interactions between positively charged nitrogen groups in QAC and negatively charged compounds in cell membranes [19]. In addition, there was no significant difference regarding the reduction in viable numbers of $L$. monocytogenes when the concentration of BEC exceeded $0.05 \%$. Based on these results, $0.05 \%$ was selected as the optimal concentration for BEC washing to combine with HHP.

It has been reported that washing of fresh-cut produce with sanitizers is not very effective in reducing more than $2 \log \mathrm{CFU} / \mathrm{g}$ on the produce surface [20], which is consistent with our results. To overcome the limitation of washing with sanitizers, a novel hurdle technology that increases the inactivation effect of washing with a sanitizer, such as BEC, is needed. HHP is a physical treatment that can inactivate microorganisms without affecting the quality of foods [9]. Thus, HHP was chosen to be combined with BEC washing in this study.

\section{Combined HHP and BEC Washing}

To decide the optimal condition for HHP treatment, the inactivation effect of HHP treatment at 200 or $400 \mathrm{MPa}$ for $5 \mathrm{~min}$ against L. monocytogenes attached to FCB was compared (data not shown). The log-reduction in the population of L. monocytogenes on FCB after HHP treatment at $200 \mathrm{MPa}$ was only $0.64 \mathrm{log} \mathrm{CFU} / \mathrm{g}$, whereas $\mathrm{HHP}$

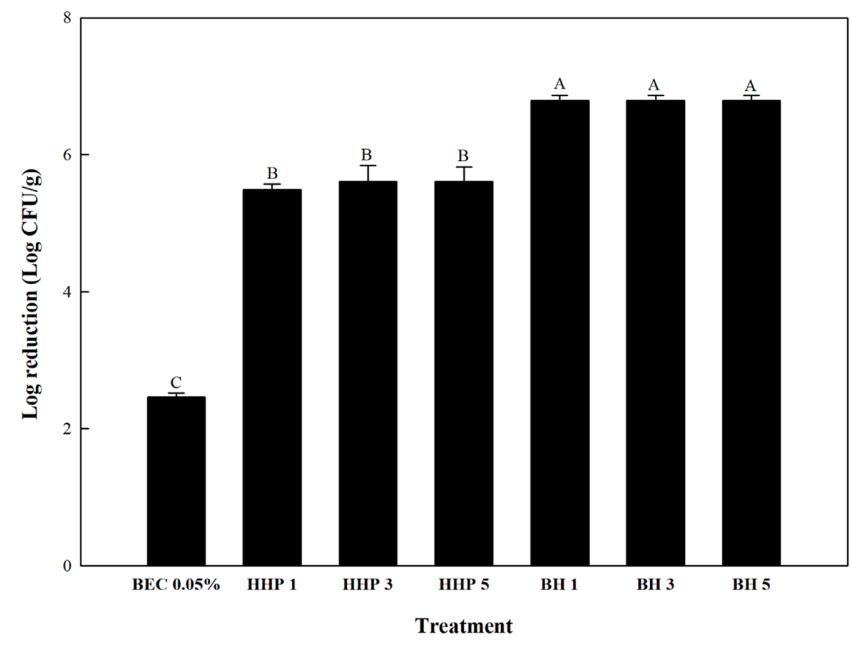

Fig. 2. Log reductions in the population of L. monocytogenes inoculated on fresh-cut broccoli by various treatments.

BEC $0.05 \%, 0.05 \%$ BEC washing; HHP 1, 3, 5, High hydrostatic pressure at $400 \mathrm{MPa}$ for 1, 3, and $5 \mathrm{~min}$, respectively; $\mathrm{BH} \mathrm{1,} \mathrm{3,} \mathrm{5,}$ Combined treatment of HHP 1, 3, and 5, respectively, followed by $0.05 \%$ BEC washing. ${ }^{A-C}$ Any means with different letters are significantly different $(p<0.05)$ by Duncan's multiple range test.

treatment at $400 \mathrm{MPa}$ for $5 \mathrm{~min}$ produced a 5.62 logreduction in the population of L. monocytogenes attached to FCB. These results agreed with a previous report that the bactericidal effect of HHP occurs at more than $400 \mathrm{MPa}$ [9]. Along with these results, the optimal pressure of HHP treatment was determined to be $400 \mathrm{MPa}$, and the inactivation effect of $\mathrm{HHP}$ treatment was compared at different treatment times (1,3, and $5 \mathrm{~min})$. Fig. 2 shows the inactivation effects of $0.05 \% \mathrm{BEC}$ washing alone, HHP at $400 \mathrm{MPa}$ for 1,3 , and $5 \mathrm{~min}$ alone, and the combined treatment with HHP treatment and BEC washing against L. monocytogenes inoculated on FCB. The log-reductions in the population of $L$. monocytogenes on FCB after the treatment with HHP for 1, 3, and 5 min were 5.49, 5.61, and $5.62 \log \mathrm{CFU} / \mathrm{g}$, respectively, which were not significantly different $(p>0.05)$ with increasing treatment time. These results indicated that the pressure magnitude of HHP is more important than the HHP treatment time regarding microbial inactivation. Similar to our results, Zhou et al. [21] reported an approximately 4 log-reduction in natural microorganisms on pumpkin after treatment with HHP at $450 \mathrm{MPa}$ for $5 \mathrm{~min}$. Dong et al. [22] also reported that the population of foodborne pathogens contaminating lotus root was decreased by 4-5 $\log \mathrm{CFU} / \mathrm{g}$ with the treatment of $\mathrm{HHP}$ at more than $400 \mathrm{MPa}$. As shown in several studies, HHP treatment alone produces considerable inactivation of 

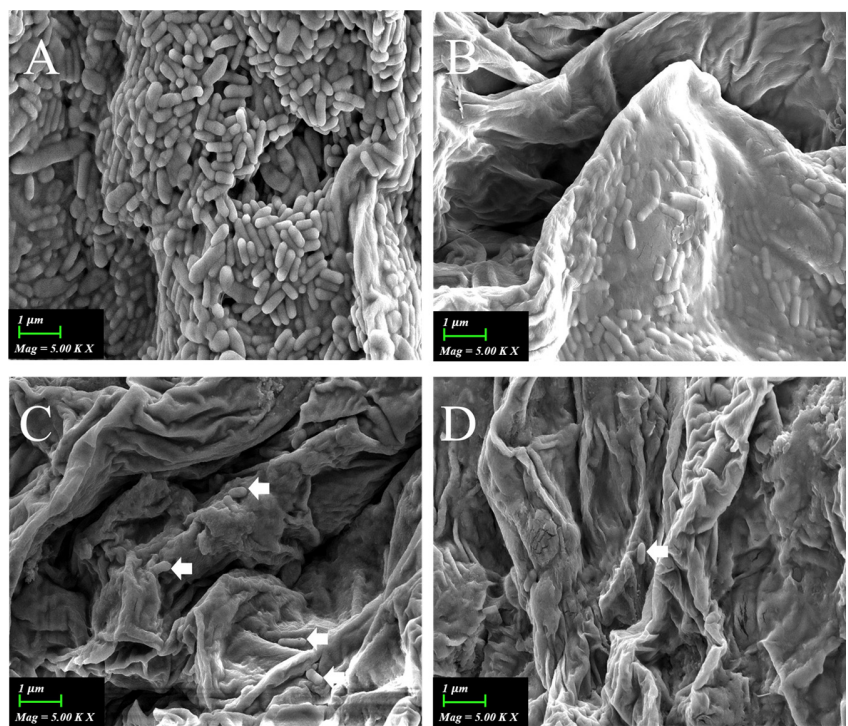

Fig. 3. SEM images (Magnification: 5,000 $\times$ ) of L. monocytogenes inoculated on fresh-cut broccoli after the combined treatment of HHP and BEC washing.

A, Non-treated control; B, 0.05\% BEC washing; C, HHP at $400 \mathrm{MPa}$ for $1 \mathrm{~min}$ (HHP 1); D, Combined treatment of HHP 1 and $0.05 \%$ BEC washing.

various microorganisms on fresh-cut produce. However, there is still the risk of re-growth of the few surviving microorganisms.

In contrast, most of the L. monocytogenes populations inoculated on FCB surface were inactivated (less than the detection limit of $1 \log \mathrm{CFU} / \mathrm{ml}$ ) by the combined treatment with $\mathrm{HHP}$ and $0.05 \%$ BEC washing. In agreement with the results obtained by HHP treatment alone, there was no significant difference $(p>0.05)$ in the inactivation effect of the combined treatment according to treatment time (Fig. 3). Based on these results, it is considered that the optimal processing condition of HHP treatment with BEC washing is $400 \mathrm{MPa}$ for $1 \mathrm{~min}$. The main inactivation mechanism of HHP treatment is the formation of pores in the bacterial membranes due to the high pressure, which leads to cell death because of the leakage of cell constituents [10]. In addition, QACs, such as BEC, are cationic surfactants that react directly with the negatively charged bacterial membranes by electrostatic interactions and kill the microorganisms due to membrane destruction [19]. In this study, the combined treatment with HHP and BEC washing was performed in a sequential manner. Thus, the effective inactivation effect by the combined treatment was generated due to multiple actions of each single treatment. Therefore, the combined treatment with HHP at
$400 \mathrm{MPa}$ for $1 \mathrm{~min}$ and $0.05 \%$ BEC washing could be used as a novel hurdle technology to improve the microbial safety of FCB.

To visually observe the inactivation effect of the combined treatment with $\mathrm{HHP}$ at $400 \mathrm{MPa}$ for 1 min and $0.05 \%$ BEC washing, SEM of the treated and non-treated samples was done (Fig. 3). Many intact L. monocytogenes were observed on the surface of non-treated FCB samples. After washing with $0.05 \% \mathrm{BEC}$, the morphology of L. monocytogenes was marginally changed compared to that of the non-treated control, and a considerable portion of the L. monocytogenes population on the FCB was no longer evident (Fig. 3). However, there were still L. monocytogenes on the FCB surface, even though there were substantially fewer compared to the control. Thus, there was a potential risk about re-growth of surviving L. monocytogenes on FCB. In contrast, HHP treatment alone and the combined treatment more effectively removed L. monocytogenes cells on FCB than BEC washing, and consequently most of the bacterial cells disappeared (Fig. 3). In the SEM images, HHP treatment alone and the combined treatment showed a similar pattern. However, as confirmed by the microbial enumeration results (Fig. 2), the combined treatment with HHP and BEC washing produced a markedly more powerful inactivation effect of $L$. monocytogenes on FCB. Ritz et al. [23] reported that when HHP treatment alone at $400 \mathrm{MPa}$ for $10 \mathrm{~min}$ was applied to L. monocytogenes, some cells appeared to divide, but the population maintained the normal morphology. These results clearly suggest that the combined treatment of HHP and BEC washing more efficiently inactivates the $L$. monocytogenes foodborne pathogen on FCB surface than each single treatment.

\section{Quality Changes in FCB after the Combined Treatment}

To examine the effect of each treatment on the quality of FCB, changes in color, especially yellowness (Hunter color b value), degree of browning, hardness, and GLS content in FCB after single or combined treatment with HHP and BEC washing were measured (Tables 1 and 2). Browning is an undesirable color change that indicates the deterioration of commercial quality in fresh-cut produce. It is a major problem in the fresh-cut produce industry [15]. In this study, the degree of browning in FCB samples after the treatments was determined by measuring Hunter color $b$ value and browning index (Table 1 ). The Hunter $b$ value of non-treated control samples was 19.08 and there was no significant difference $(p>0.05)$ among all treatments (Table 1). Browning index represents the content of watersoluble pigments produced by the browning reaction [15]. 
Table 1. Color properties of fresh-cut broccoli after the combined treatment of HHP and $0.05 \%$ BEC washing.

\begin{tabular}{lcc}
\hline Treatment & b value & Browning index \\
\hline Control & $19.08 \pm 0.47^{\mathrm{A}}$ & $0.10 \pm 0.01^{\mathrm{A}}$ \\
Water & $19.55 \pm 0.76^{\mathrm{A}}$ & $0.09 \pm 0.01^{\mathrm{A}}$ \\
$0.05 \%$ BEC & $19.36 \pm 0.64^{\mathrm{A}}$ & $0.09 \pm 0.02^{\mathrm{A}}$ \\
HHP 1 & $19.38 \pm 0.29^{\mathrm{A}}$ & $0.10 \pm 0.01^{\mathrm{A}}$ \\
HHP 3 & $19.35 \pm 0.41^{\mathrm{A}}$ & $0.09 \pm 0.01^{\mathrm{A}}$ \\
HHP 5 & $19.25 \pm 0.30^{\mathrm{A}}$ & $0.10 \pm 0.02^{\mathrm{A}}$ \\
BH 1 & $19.62 \pm 0.26^{\mathrm{A}}$ & $0.11 \pm 0.01^{\mathrm{A}}$ \\
BH 3 & $19.34 \pm 0.39^{\mathrm{A}}$ & $0.10 \pm 0.02^{\mathrm{A}}$ \\
BH 5 & $19.24 \pm 0.35^{\mathrm{A}}$ & $0.11 \pm 0.02^{\mathrm{A}}$ \\
\hline
\end{tabular}

Data are presented as mean $\pm \mathrm{SD}$

Control is non-washed sample.

HHP 1, 3, and 5 are high hydrostatic pressure treatment at $400 \mathrm{MPa}$ for 1, 3, and 5 min, respectively.

BH: Combined treatment of HHP and $0.05 \%$ BEC washing.

${ }^{A}$ Any means in the same column are not significantly different $(p>0.05)$ by Duncan's multiple range test.

There was also no significant difference $(p>0.05)$ in browning index of the samples among treatments (Table 1). Similarly, many reports applying various sanitizers or HHP to several types of fresh produce have also showed the absence of browning reactions [17, 21, 22]. The collective results indicate that the single or the combined treatment with HHP and BEC washing did not affect the color quality of FCB.

Hardness is an important factor indicating the commercial quality of fresh-cut produce [24]. The hardness of nontreated FCB was $51.70 \mathrm{~N}$, and there was no significant difference $(p>0.05)$ in the hardness of non-treated control and FCB samples treated by washing with water, $0.02 \%$ $\mathrm{NaOCl}$, and $0.05 \%$ BEC (Table 2). Similar to our results, it has been reported that various types of sanitizers used as a washing agent do not affect the hardness of fresh-cut produce [17]. In contrast, the hardness of the samples treated with HHP alone or in combination with BEC washing slightly decreased with increasing HHP treatment time (Table 2). The reason for this decrease could be due to the impact of HHP. The tissue damage in the fresh-cut produce by HHP has been confirmed [21, 25]. Similarly, Zhou et al. [21] (2014) reported that HHP treatment at $450 \mathrm{MPa}$ for $15 \mathrm{~min}$ or $550 \mathrm{MPa}$ for $10 \mathrm{~min}$ decreased the hardness in pumpkin by $42.8 \%$ and $32.3 \%$, respectively, compared to the control samples. In contrast, HHP treatment applied in this study slightly decreased the hardness in FCB by only $6.2 \%$ to $9.7 \%$ compared to non-
Table 2. Total glucosinolate content and hardness of fresh-cut broccoli after the combined treatment of HHP and 0.05\% BEC washing.

\begin{tabular}{lcc}
\hline Treatment & $\begin{array}{c}\text { Hardness } \\
(\mathrm{N})\end{array}$ & $\begin{array}{c}\text { Total glucosinolate } \\
\text { content } \\
(\mu \mathrm{mol} / \mathrm{g} \mathrm{dw})\end{array}$ \\
\hline Control & $51.70 \pm 1.55^{\mathrm{AB}}$ & $23.27 \pm 0.71^{\mathrm{B}}$ \\
Water & $52.44 \pm 1.79^{\mathrm{A}}$ & $21.77 \pm 0.33^{\mathrm{B}}$ \\
BEC 0.05\% & $51.72 \pm 1.23^{\mathrm{AB}}$ & $25.10 \pm 0.59^{\mathrm{B}}$ \\
HHP 1 & $48.48 \pm 2.89^{\mathrm{AB}}$ & $31.16 \pm 1.32^{\mathrm{A}}$ \\
HHP 3 & $47.49 \pm 1.84^{\mathrm{AB}}$ & $31.81 \pm 1.07^{\mathrm{A}}$ \\
HHP 5 & $46.91 \pm 1.51^{\mathrm{B}}$ & $32.21 \pm 0.59^{\mathrm{A}}$ \\
BH 1 & $47.14 \pm 0.52^{\mathrm{AB}}$ & $31.60 \pm 4.66^{\mathrm{A}}$ \\
BH 3 & $48.19 \pm 1.94^{\mathrm{AB}}$ & $36.58 \pm 0.78^{\mathrm{A}}$ \\
BH 5 & $46.71 \pm 3.50^{\mathrm{B}}$ & $4.00^{\mathrm{A}}$ \\
\hline
\end{tabular}

Data are presented as mean \pm SD.

Control is non-washed sample.

HHP 1, 3, and 5 are high hydrostatic pressure treatment at $400 \mathrm{MPa}$ for 1, 3, and 5 min, respectively.

BH: Combined treatment of HHP and $0.05 \%$ BEC washing.

${ }^{\mathrm{A}-\mathrm{B}}$ Any means in the same column with different letters are significantly different $(p<0.05)$ by Duncan's multiple range test.

treated control samples (Table 2). Therefore, the combined treatment used in this study has potential as a novel method to effectively inactivate pathogenic bacteria contaminated on FCB with minimal quality changes in FCB.

GLS is a secondary metabolite that is mainly present in the Brassicaceae family such as broccoli [2, 26]. After treatments, including with chemical sanitizer, it is necessary to maintain the content of GLS in broccoli to ensure a bioactivity that is beneficial to humans [27]. The total GLS content in the non-treated FCB sample was $23.27 \mu \mathrm{mol} / \mathrm{g}$ $\mathrm{dw}$ (Table 2), similar to the result of Van Eylen et al. [28]. In contrast, there were slight increases in the total GLS content for the samples treated with HHP alone or the combined treatment with HHP and BEC washing, compared to the control, water, and BEC washing. In general, HHP treatment under high pressure reduces total GLS content in many types of fresh produce due to the reactions between myrosinase and GLS during the breakdown of tissues [29]. On the contrary, an increase in total GLS content was observed in this study (Table 2). GLS comprises aliphatic GLS, indole GLS, aromatic GLS, and others [28, 29]. Although some types of GLS are easily broken down by myrosinase during HHP treatment, some GLS, such as progoitrin and glucoraphanin, could have increased after the treatment [29]. The exact mechanism of increase in the 
content of GLS in fresh produce by HHP treatment has not been clarified. Van Eylen et al. [28] also reported that total GLS content in broccoli heads did not decrease when broccoli was treated with HHP at 100-500 MPa for $15 \mathrm{~min}$, which was a longer treatment time than that of our study. Thus, these results indicate that the HHP treatment used in this study can be more effective in maintaining the content of GLS in broccoli. However, further studies should be performed to reveal why the content of GLS in broccoli was increased by HHP treatment. Overall, based on these results, the combined treatment with $\mathrm{HHP}$ and $0.05 \%$ BEC washing has potential value as an effective hurdle technology to inactivate foodborne pathogens on FCB without adversely affecting the quality of the product. It should also be noted that further studies are needed to enhance the feasibility of the combined treatment developed in this study and find an effective way of HHP use regarding economic aspect.

\section{Conflict of Interest}

The authors have no financial conflicts of interest to declare.

\section{References}

1. Collazo C, Lafarga T, Aguiló-Aguayo I, Marín-Sáez J, Abadias M, Viñas I. 2018. Decontamination of fresh-cut broccoli with a water-assisted UV-C technology and its combination with peroxyacetic acid. Food Control 93: 92-100.

2. Paulsen E, Barrios S, Baenas N, Moreno DA, Heinzen H, Lema P. 2018. Effect of temperature on glucosinolate content and shelf life of ready-to-eat broccoli florets packaged in passive modified atmosphere. Postharvest Biol. Technol. 138: 125-133.

3. Alvarez MV, Ponce AG, Moreira MDR. 2013. Antimicrobial efficiency of chitosan coating enriched with bioactive compounds to improve the safety of fresh cut broccoli. LWT-Food Sci. Technol. 50: 78-87.

4. U.S. Food and Drug Administration (FDA) (2018). Stop \& Shop voluntarily recalls Stop \& Shop frozen broccoli cuts. Available from https://www.fda.gov/Safety/Recalls/ucm609000 Accessed March 11, 2019.

5. Gil MI, Selma MV, López-Gálvez F, Allende A. 2009. Freshcut product sanitation and wash water disinfection: Problems and solutions. Int. J. Food Sci. Technol. 134: 37-45.

6. Meireles A, Giaouris E, Simões M. 2016. Alternative disinfection methods to chlorine for use in the fresh-cut industry. Food Res. Int. 82: 71-85.
7. Ramos B, Miller FA, Brandão TR, Teixeira P, Silva CL. 2013. Fresh fruits and vegetables-an overview on applied methodologies to improve its quality and safety. Innov. Food Sci. Emerg. Technol. 20: 1-15.

8. Kang JH, Park JB, Song KB. 2019. Inhibitory activities of quaternary ammonium surfactants against Escherichia coli O157: H7, Salmonella Typhimurium, and Listeria monocytogenes inoculated on spinach leaves. LWT-Food Sci. Technol. 102: 284-290.

9. Kimura K, Inaoka T, Yamamoto K. 2018. Metabolome analysis of Escherichia coli ATCC25922 cells treated with high hydrostatic pressure at 400 and $600 \mathrm{MPa}$. J. Biosci. Bioeng. 126: 611-616.

10. Rendueles E, Omer MK, Alvseike O, Alonso-Calleja C, Capita R, Prieto M. 2011. Microbiological food safety assessment of high hydrostatic pressure processing: a review. LWT-Food Sci. Technol. 44: 1251-1260.

11. Jung LS, Lee SH, Kim S, Cho Y, Ahn J. 2014. Effect of highpressure post-packaging pasteurization on microbiological quality of ready-to-use vegetables. J. Food Process. Preserv. 38: 406-412.

12. Khan I, Tango CN, Miskeen S, Lee BH, Oh DH. 2017. Hurdle technology: a novel approach for enhanced food quality and safety-A review. Food Control 73: 1426-1444.

13. Klintham P, Tongchitpakdee S, Chinsirikul W, Mahakarnchanakul W. 2017. Combination of microbubbles with oxidizing sanitizers to eliminate Escherichia coli and Salmonella Typhimurium on Thai leafy vegetables. Food Control 77: 260-269.

14. Park JB, Kang JH, Song KB. 2018. Improving the microbial safety of fresh-cut endive with a combined treatment of cinnamon leaf oil emulsion containing cationic surfactants and ultrasound. J. Microbiol. Biotechnol. 28: 503-509.

15. Kim DH, Kim HB, Chung HS, Moon KD. 2014. Browning control of fresh-cut lettuce by phytoncide treatment. Food Chem. 159: 188-192.

16. Mawlong I, Sujith Kumar MS, Gurung B, Singh KH, Singh D. 2017. A sim ple spectrophotometric method for estimating total glucosinolates in mustard de-oiled cake. Int. J. Food Prop. 20: 3274-3281.

17. Park JB, Kang JH, Song KB. 2019. Clove bud essential oil emulsion contain ing benzethonium chloride inactivates Salmonella Typhimurium and Listeria monocytogenes on freshcut pak choi during modified atmosphere storage. Food Control 100: 17-23.

18. Yuan W, Teo CHM, Yuk HG. 2019. Combined antibacterial activities of essen tial oil compounds against Escherichia coli O157: H7 and their application potential on fresh-cut lettuce. Food Control 96: 112-118.

19. Bazina L, Maravić A, Krce L, Soldo B, Odžak R, Popović $\mathrm{VB}$, et al. 2019. Discovery of novel quaternary ammonium compounds based on quinuc lidine-3-ol as new potential antimicrobial candidates. Eur. J. Pharm. Sci. 163: 626-635. 
20. Olaimat AN, Holley RA. 2012. Factors influencing the microbial safety of fresh produce: a review. Food Microbiol. 32: 1-19.

21. Zhou CL, Liu W, Zhao J, Yuan C, Song Y, Chen D, et al. 2014. The effect of high hydrostatic pressure on the microbiological quality and physical-chemical characteristics

of Pumpkin (Cucurbita maxima Duch.) during refrigerated storage. Innov. Food Sci. Emerg. Technol. 21: 24-34.

22. Dong P, Kong M, Yao J, Zhang Y, Liao X, Hu X, et al. 2013. The effect of high hydrostatic pressure on the microbiological quality and physicochemical properties of lotus root during refrigerated storage. Innov. Food Sci. Emerg. Technol. 19: 79-84.

23. Ritz M, Tholozan JL, Federighi M, Pilet MF. 2002. Physiological damages of Listeria monocytogenes treated by high hydrostatic pressure. Int. J. Food Microbiol. 79: 47-53.

24. Toivonen PM, Brummell DA. 2008. Biochemical bases of appearance and texture changes in fresh-cut fruit and vegetables. Postharvest Biol. Technol. 48: 1-14.

25. Yi J, Feng H, Bi J, Zhou L, Zhou M, Cao J, Li J. 2016. High hydrostatic pressure induced physiological changes and physical damages in asparagus spears. Postharvest Biol. Technol. 118: 1-10.

26. Hong E, Kim SJ, \& Kim GH. 2011. Identification and quantitative determination of glucosinolates in seeds and edible parts of Korean Chinese cabbage. Food Chem. 128: 1115-1120.

27. Tian M, Xu X, Liu Y, Xie L, Pan S. 2016. Effect of Se treatment on glucosinolate metabolism and health-promoting compounds in the broccoli sprouts of three cultivars. Food Chem. 190: 374-380.

28. Van Eylen D, Bellostas N, Strobel BW, Oey I, Hendrickx M, Van Loey A, et al. 2009. Influence of pressure/temperature treatments on glucosinolate conv-ersion in broccoli (Brassica oleraceae L. co Italica) heads. Food Chem. 112: 646-653.

29. Clariana M, Valverde J, Wijngaard H, Mullen AM, Marcos B. 2011. High pressure processing of swede (Brassica napus): Impact on quality properties. Innov. Food Sci. Emerg. Technol. 12: $85-92$. 